\title{
$A$ hereditariedade mórbida: de Kraepelin aos neokraepelinianos
}

\section{| ' Sandra Caponi |}

Resumo: Analisamos aqui as referências que Emil Kraepelin dedica à problemática da herança mórbida. Estudamos a persistência e continuidade das principais teses de Kraepelin, incluída a etiologia hereditária de patologias mentais, na Psiquiatria contemporânea que se define como neokraepeliniana. Com esse objetivo, analisamos inicialmente as articulações teóricas e conceituais que existem entre a ideia de constituição mórbida e as estratégias propostas por Kraepelin para a realização das entrevistas psiquiátricas. A seguir, consideramos o lugar reservado aos estudos dedicados à herança mórbida no contexto histórico de surgimento da psiquiatria neokraepeliniana, especificamente a partir da elaboração do DSM III.

> Palavras-chave: hereditariedade; doença mental; Kraepelin; DSM; degeneração.

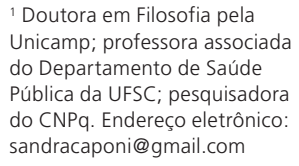

Recebido em: 22/07/2010. Aprovado em: 16/10/2010. 
A psiquiatria moderna considera que a maior contribuição de Emil Kraepelin (1907) a esse campo de conhecimento foi sua distinção entre loucura maníacodepressiva e demência precoce (hoje denominada esquizofrenia) (HORWITZ, 2007), tendo como referência principal o prognóstico diferenciado das doenças. Kraepelin entende que uma psiquiatria científica deveria poder articular os estudos etiológicos com aqueles referidos ao curso, à evolução e às possibilidades de reversão do quadro clínico, sem limitar-se, como os alienistas, à simples descrição de sintomas. Assim, o Manual de Psiquiatria (1904), em sua sétima edição, apresenta como uma de suas contribuições mais relevantes um método unificado para examinar os pacientes, onde a questão da hereditariedade adquire relevância para compreender a etiologia das patologias mentais. Nesse ponto existem algumas significativas coincidências entre Kraepelin e os psiquiatras franceses da segunda metade do século XIX, como Morel (1857) e Magnan (1893), obcecados pela questão da hereditariedade mórbida e degeneração. Analisamos aqui a semelhança de algumas teses defendidas por Kraepelin sobre herança mórbida com a teoria da degeneração, para interrogarmos sobre a persistência das teses de Kraepelin na psiquiatria contemporânea, especificamente aquela que, após a publicação do DSM III, se reconhece como herdeira dos princípios neokraepelinianos.

A problemática da hereditariedade mórbida teve considerável influência na psiquiatria do século XIX, particularmente quando Morel e seus sucessores estabeleceram a associação entre patologias psiquiátricas e degeneração hereditária. Assim, e perante a dificuldade de achar marcas no corpo, especificamente no cérebro, que permitissem uma explicação biológica das patologias mentais, diversos psiquiatras recorreram a explicações hereditárias dessas doenças, sem por isso renunciar à procura de explicações anatômicas ou cerebrais. Essas explicações hereditárias estavam fundamentalmente baseadas na repetição de uma ampla variedade de patologias que podiam ser observadas nas diversas geraçóes de uma mesma família. As patologias podiam reaparecer de maneira idêntica ou com amplas variaçóes. No primeiro caso, se falava de herança similar, e no segundo, de herança dissimilar (MOREL, 1857), possibilitando a explicação da ocorrência de patologias mentais, por exemplo, nos filhos de alcoólatras ou sifilíticos.

Utilizamos aqui o conceito de hereditariedade mórbida por referência a esse marco explicativo ambíguo das doenças mentais que envolve o grande corpo das famílias afetadas pelas mais diversas patologias (FOUCAULT, 1999; COFFIN, 
2003). Como tentaremos mostrar, esse marco explicativo não é exclusivo dos teóricos da degeneração; ele permanece no discurso de Kraepelin e da psiquiatria biológica, muitas vezes como aliado, outras vezes como substitutivo da preocupação por achar no corpo, particularmente nas lesões ou nas alterações cerebrais, a causa de todas as patologias psiquiátricas ou psíquicas.

Assim, se analisamos o método defendido por Kraepelin em seu Manual de Psiquiatria, veremos que pretende definir uma "rotina definitiva, que o estudante deve utilizar diante de seus pacientes" (KRAEPELIN, 1907, p. 97), na qual o registro de fatores hereditários tem absoluto predomínio sobre as referências aos contextos de vida dos pacientes, nos quais aparecem os sofrimentos psíquicos. Essa rotina metodológica tem quatro momentos ou passos que deverão ser sucessivamente seguidos: (1) a anamnese da família; (2) a história pessoal do paciente anterior à doença; (3) a anamnese da doença e (4) o status praesens (termo utilizado para designar a descrição das condiçôes do paciente no momento em que chegou à observação médica).

O primeiro item é considerado por Kraepelin como absolutamente relevante e está relacionado diretamente à compreensão da etiologia da doença:

A importância da herança como fator etiológico requer uma cuidadosa compreensão da história familiar, não somente no que se refere à presença de doenças mentais ou neurológicas, mas também com a finalidade de evidenciar a existência de uma constituição física defeituosa. (KRAEPELIN, 1907, p. 98)

Não é suficiente fazer uma lista de patologias mentais dos familiares; essa anamnese não pode limitar-se a perguntas gerais sobre ocorrência de patologias. Requer, como afirma Kraepelin, um detalhado inquérito sobre hábitos, traços e doenças de todos os ramos diretos da família, dedicando atenção especial a detalhes sobre particularidades mentais, consumo de álcool, adiçôes, tendências criminosas, etc.

O segundo momento metodológico exige maior detalhamento, que pode trazer importantes indícios para compreender o quadro patológico do indivíduo e da família. As questôes da entrevista devem referir-se à gestação e parto, às doenças da infância, a choques emocionais e traumas sofridos no momento do nascimento. Lembremos que todos esses elementos faziam parte das questôes que, de acordo com Magnan (1893) e os teóricos da degeneração, ${ }^{1}$ deveriam ser consideradas para poder identificar os quadros de herança patológica. $\mathrm{O}$ interrogatório não devia limitar-se a descrever a sucessão de patologias presentes nas famílias, devendo 
observar também a progressão crescente de síndromes num mesmo indivíduo ao longo de sua vida. Por essa razão, acreditava que entender as dificuldades da infância podia esclarecer tanto o diagnóstico atual quanto o prognóstico.

Assim, para Kraepelin, tornavam-se relevantes todos os dados referentes a sequelas de doenças infecciosas, convulsões na infância, dificuldades de aprendizagem, lentidão para falar, caminhar ou compreender, assim como o momento em que aparecem os impulsos sexuais, a aparição da menstruação, dando particular atenção aos hábitos de masturbação, sua frequência e ao momento em que se inicia essa prática. Por fim, essa análise detalhada deverá continuar com um interrogatório sobre os hábitos alimentares do paciente, sua relação com bebidas e drogas, suas idiossincrasias, se é um individuo egoísta, se trabalha, o tipo de trabalho que realiza, quando iniciou essa atividade. Para que esse interrogatório pudesse ser realizado de modo correto, Kraepelin adverte que todo estudante deve compreender que a formulação de perguntas gerais é inteiramente inadequada, e que uma correta anamnese será aquela que se desenvolva com perguntas específicas, bem dirigidas, que não deixem lugar para a fala do paciente (KRAEPELIN, 1907). Cada um desses elementos deve ser considerado para poder determinar a causa e o diagnóstico de uma doença.

Em relação ao último momento dessa rotina metodológica, denominada status proenses, este devia incluir tanto as observações físicas quanto as mentais, porém Kraepelin considerava relevante iniciar pela observação das condiçōes físicas externas. Primeiro devia ser descartada a existência de doenças crônicas como tuberculoses ou sífilis, para logo iniciar uma detida observação das características do paciente, que inclui a enumeração de "estigmatas físicos, como malformações do palato ou dos órgãos sexuais, estrabismo congênito, albinismo, posição errada dos dentes, dos olhos, etc.” (KRAEPELIN, 1907, p. 99). Essas observaçôes deverão ser seguidas pelo exame do sistema nervoso, com medidas do crânio que indicam o desenvolvimento do córtex cerebral e se existe desproporção entre o tamanho da cabeça e o do corpo. O exame da posição dos olhos permitiria revelar certas doenças, assim como "um cuidadoso exame das orelhas poderia revelar, às vezes, uma causa suficiente para alucinações" (Ibidem.).

Se observarmos a etiologia dos dois principais grupos patológicos diferenciados por Kraepelin, podemos ver que a hereditariedade está presente em ambos: de maneira inequívoca na demência precoce, de maneira menos uniforme na loucura 
maníaco-depressiva. Em ambos os casos, estamos perante patologias endógenas, ainda que eventualmente possam existir loucuras maníacas ou depressivas que podem ser consideradas exógenas. Assim, referindo-se à etiologia da demência precoce, Kraepelin afirma:

O defeito hereditário é o verdadeiro fator proeminente, sendo que aparece em 70\% dos casos estudados [...]. Isso varia nas diferentes formas de demência, sendo maior nas formas catatônicas e hebefrênica. [...] Vários estigmatas físicos podem ser achados com frequência, como malformação do crânio, orelhas, palato, estrabismo, fraqueza geral ou mamilos supranumerários. (KRAEPELIN, 1907, p. 219).

Uma explicação etiológica semelhante aparece por referência à loucura maníaco-depressiva, que corresponde a um número que oscila entre 20 e $30 \%$ de admissões no hospital psiquiátrico. Sobre os fatores etiológicos dessa patologia, Kraepelin dirá que:

uma herança defeituosa (patológica) é o mais importante, ocorrendo em 70 ou $80 \%$ dos
casos. Uma base constitucional defeituosa é evidente nos indivíduos, prévia à manifes-
tação da loucura, alguns são claramente anormais, outros tem uma disposição excitável
com mudanças de humor, outros são muito reservados, outros idiotas de nascimento.
Estigmatas físicos podem também estar presentes. (KRAEPELIN, 1907, p. 382).

Poderíamos continuar essa descrição com outras patologias que apresentam etiologias semelhantes; mas se observarmos o modo como Kraepelin descreve o subgrupo de patologias mentais, que denomina "insanidades de degeneração", veremos que a etiologia das mesmas é muito semelhante à de outras patologias por ele definidas, pois para ele o principal sintoma que define os estados constitucionais patológicos é a elaboração mórbida de estímulos normais que se manifestam por meio de sentimentos e pensamentos perturbados. E para que esse estado constitucional patológico ocorra, deve existir uma constituição mórbida prévia. "A partir desse quadro geral, desenvolvem-se as insanidades por degeneração, que são difíceis de agrupar, porque existem inúmeras combinações e estados intermediários (border-line states)" (KRAEPELIN, 1907, p. 485).

A dificuldade para estabelecer limites entre insanidades por degeneração e outras patologias talvez nos permita entender a repetição de referências a configurações hereditárias patológicas que aparecem como explicação etiológica privilegiada para muitas das doenças analisadas por Kraepelin. Deve-se destacar que as explicações hereditárias de patologias mentais não foram utilizadas exclusivamente pelos teóricos da degeneração e por Kraepelin, a preocupação 
pela hereditariedade mórbida está presente na psiquiatria biológica das primeiras décadas do século XX, como pode observar-se, por exemplo, no Manual de psiquiatria de Fursac, publicado na França em 1909 e amplamente utilizado nos anos que antecederam à Primeira Guerra Mundial (COFFIN, 2003, p. 237).

Uma última dificuldade apresentada pelas patologias de degeneração é sua limitada possibilidade de reversibilidade e cura. A cura das doenças mentais hereditárias considerava-se extremamente difícil ou impossível, e o destino para a maior parte dos sujeitos com essa constituição mórbida raramente poderia ser diferente do encerramento institucional. Essa dificuldade aparecia de maneira clara tanto nos teóricos da degeneração como em Kraepelin. Já Morel falava de uma quarta geração de degenerados destinada à esterilidade, e Magnan achava prudente limitar os casamentos dos sujeitos afetados por patologias hereditárias como medida preventiva. Kraepelin, por sua vez, dará continuidade ao mesmo esquema explicativo. Partindo da dificuldade para definir uma terapêutica bem-sucedida para as patologias mentais herdadas, insistirá na necessidade de estabelecer medidas profiláticas que permitam antecipar e evitar a aparição da doença.

Em relação à recuperação dos chamados "estados psicopáticos constitucionais", Kraepelin declara-se pouco otimista. O prognóstico é, em geral, pouco favorável quanto às degenerações hereditárias, exceto em alguns poucos casos. Em linhas gerais, ele se refere à incurabilidade de certas patologias, justamente por se tratar de constituições mórbidas. Tal é o caso das "onomatomanias", diagnóstico que retoma de Magnan, considerada uma das patologias de degeneração com prognóstico desfavorável para a qual unicamente fica a possibilidade de prevenção. O mesmo ocorre com a neurastenia ou com a insanidade compulsiva. Referindose a esta última patologia, Kraepelin diz:

A profilaxia é da maior importância. Pessoas defeituosas (com traços de degeneração) devem ser dissuadidas de se casarem umas com as outras. Influências nocivas devem ser combatidas, o alcoolismo principalmente. Quando crianças, os pais devem ter atenção especial com a educação, que deve se referir tanto ao corpo quanto à alma. O desenvolvimento mental deve ser atrasado se existem sinais de precocidade. (KRAEPELIN, 1907, p. 491)

Em outros casos, Kraepelin recomendará confinamentos e isolamentos em instituiçôes psiquiátricas por curtos períodos, sem desconsiderar que frequentemente esses ingressos acabam sendo permanentes. As insanidades por degeneração são, em sua grande maioria, consideradas doenças com prognóstico 
desfavorável (KRAEPELIN, 1907), existindo a possibilidade de aparição de síndromes periódicas, como no caso da agorafobia. No entanto, as estratégias de intervenção privilegiadas para combater a condição de degeneração estão centradas na prevenção, fundamentalmente na educação dos jovens.

No caso da homossexualidade, o prognóstico é mais favorável. Kraepelin considera que se trata de uma enfermidade que em muitos casos pode ser revertida. Apresenta estratégias terapêuticas consideradas bem-sucedidas, como o método da hipnose. Os passos desse método descrito por Kraepelin são: (1) inicia-se com hipnose direcionada contra o aumento da excitação sexual e contra a masturbação; (2) logo se direciona para promover a insensibilidade do paciente a seu próprio sexo; (3) finalmente cria-se excitabilidade ao sexo oposto e aos vínculos heterossexuais (KRAEPELIN, 1907, p. 514). Com essa estratégia, Kraepelin considera que é possível restituir o interesse do paciente pelo sexo oposto e levá-lo a desistir de sua compulsão pelo próprio sexo.

Para concluir estas reflexões, não podemos deixar de lembrar um texto de Kraepelin, originariamente publicado em 1920, denominado "As formas de manifestação da insanidade" (2009). Nesse texto Kraepelin apresenta uma oposição frontal às teses defendidas pela psicanálise. Logo no início, o autor afirma que geralmente existem duas formas de chegar a um entendimento aprofundado das doenças. A primeira forma se refere às relaçooes de empatia, que Kraepelin define como um

poético sentimento que nos coloca em sintonia com os processos anímicos que
ocorrem no outro [...]. A 'empatia' é um procedimento bastante inseguro que,
ainda que seja indispensável para a aproximaçáo entre os seres humanos e para a
criação poética, como meio auxiliar de pesquisa, pode levar aos maiores enganos.
(KRAEPELIN, 2009, p. 171)

Perante o fracasso da empatia, aparece a segunda forma possível, considerada científica, de entender as doenças. Em primeiro lugar, será necessário excluir qualquer pretensão de escuta daquilo que o paciente tem a dizer. Para Kraepelin, é indispensável considerar como parte desse método que a fala ou a narrativa do paciente será o veículo de inevitáveis enganos e mentiras próprias de seu estado patológico (KRAEPELIN, 2009 [1809]).

$\mathrm{Na}$ abordagem científica e objetiva privilegiada por Kraepelin, os dados mais relevantes serão aqueles referentes ao entendimento das condições prévias ao surgimento da patologia. Como afirma Kraepelin: 
Contudo, o mais importante nessa relação é descobrir o papel decisivo que cabe àquilo que é constitucional no próprio sujeito, principalmente as influências da hereditariedade [...]. Fica claro, portanto, que a compreensão das manifestações patológicas deverá passar primordialmente pela pesquisa das disposições herdadas. (KRAEPELIN, 2009, p. 174).

Assim, tanto para os teóricos da degeneração quanto para Kraepelin, a herança mórbida é aquilo que permite substituir a escuta das situaçôes concretas de vida que provocam sofrimento.

Para citar um exemplo bem corriqueiro, quero lembrá-los das explicaçôes, comuns em pacientes melancólicos, de que eles adoeceram apenas por causa deste ou daquele fracasso, ou por causa de uma mudança, ou que eles só estão preocupados com uma questão de ordem econômica, ou que apenas adoeceram de saudade por terem sido separados de seus entes queridos [...]. Depois da cura, temos a oportunidade de acompanhar a correção dessas concepções errôneas. Mas quem poderá dizer a quantas conclusões enganosas estamos expostos, se tomarmos como verdadeiras as informações dos doentes cuja veracidade não é possível comprovar? (KRAEPELIN, 2009, p. 172)

Mas se a escuta atenta à fala do outro instala a dúvida e a incerteza, que argumentos nos autorizam a supor uma certeza objetiva e científica na observação dos antecedentes familiares, nos relatos de desvios e na herança patológica? Poderíamos perguntar: quem poderá dizer a quantas conclusões enganosas estamos expostos se em lugar de ouvir o paciente aceitamos padrões hereditários de repetição como verdadeiros, ainda que essa verdade seja impossível de comprovar? Ainda que essas perguntas permaneçam até hoje sem resposta, a aceitação da herança como verdade objetiva e inquestionável permitiu excluir as narrativas dos pacientes do campo da psiquiatria. E esse, como sabemos, será o maior ponto de confluência e identificação dos neokraepelinianos com seu mestre.

\section{De Kraepelin aos neokraepelinianos}

As observações apresentadas até aqui parecem indicar que Kraepelin é um homem que pertence, quase inteiramente, ao século XIX (POSTEL, 1987, p. 365). Então deveremos nos perguntar por que razão Kraepelin atingiu o estatuto de pai da psiquiatria moderna nas últimas décadas do século XX? Como entender o ressurgimento desse modo de pensar o normal e o patológico, por décadas esquecido, e hoje recuperado por aqueles que se definem como neokraepelinianos? Para tentar compreender de que modo ocorreu a tardia recuperação de certas teses defendidas por Kraepelin, pela psiquiatria biológica 
das últimas décadas do século XX, deveremos fazer um breve relato dos acontecimentos mais destacados desse momento.

Ainda que a morte de Kraepelin tenha ocorrido em 1926, ele reingressará no século XX em 1976, a partir da iniciativa de um grupo de cientistas que se identificam com o nome de neokraepelinianos. A influência inegável que esse grupo teve na elaboração do terceiro Manual de diagnóstico e estatística de doenças psiquiátricas (APA, 1980) 3 já foi destacada por diversos historiadores e pesquisadores (AMARAL, 2004; DECKER, 2007; HORWITZ, 2007; JABLENSKY, 2007). É impossível desconsiderar a relevância que o DSM tem até hoje, assentando as bases do que será considerada uma referência obrigatória para a elaboração de diagnósticos de psiquiatras e médicos do mundo inteiro.

Não é possível fazer aqui uma história detalhada dos eventos que se sucederam a partir de 1952, ano de criação do DSM I. O objetivo é compreender de que modo as bases epistemológicas de Kraepelin reaparecem no discurso dos neokraepelinianos. Trata-se de analisar as continuidades e diferenças entre esses discursos para tentar compreender as razōes que levaram um grupo de pesquisadores de fins da década de 1970 a reconhecer como válidas as premissas construídas pela psiquiatria do século XIX, que privilegia como matriz explicativa das patologias mentais a herança mórbida e a localização cerebral. Certamente, os neokraepelinianos não serão simples seguidores das ideias do mestre; eles introduzem e inauguram um novo modo de pensar as patologias psiquiátricas que será rapidamente aceito pelos psiquiatras do mundo inteiro como referência. Para entender as razões dessa aceitação, será necessário lembrar a história que antecede o DSM IIII. O modo como a psiquiatria narra sua história recente nos permite compreender esses motivos.

Essa história leva a marca de Adolf Meyer (1866-1950), considerado referência fundamental para a psiquiatria americana no período pré e pós-guerra. Meyer se formou como professor de psiquiatria no Hospital Johns Hopkins nos anos 1910 a 1941, mas sua influência permaneceu intacta após a Segunda Guerra Mundial, pois vários de seus discípulos foram considerados figuras de liderança na psiquiatria de pós-guerra (AMARAL, 2004; DECKER, 2007; HORWITZ, 2007; JABLENSKY, 2007). Sua teoria das patologias mentais estava baseada na ideia de reação. Considerava que era indispensável observar, em cada situação precisa, o contexto em que surgem as patologias e entendê-las como reações a fatos externos. 
842 Ele apresenta uma abordagem que integra elementos da teoria freudiana sem rejeitar completamente as teorias biologistas. Por essa razão, considera-se que ele inicia a abordagem biopsicossocial de transtornos mentais. Meyer, que não aceitava a ideia de construir quadros nosológicos sem compreender os eventos da história de vida dos pacientes, influenciou profundamente a primeira tentativa de organizar uma classificação de transtornos mentais aceita pela comunidade científica americana.

Após a Segunda Guerra Mundial, os psiquiatras deviam enfrentar as sequelas sofridas pela guerra, que tinha deixado inúmeras vítimas de transtornos mentais, sem uma metodologia que pudesse ser considera adequada. Nesse marco histórico, ganharam terreno as teses defendidas pela psicanálise, difundida pelos muitos profissionais que tinham emigrado da Europa fugindo da guerra. A ideia de construir uma classificação psiquiátrica exaustiva para as doenças mentais ficava fora de consideração para os psiquiatras da APA, então profundamente influenciados pelos sucessos terapêuticos da psicanálise nos pacientes que sofriam traumas de guerra.

Meyer e seus discípulos defendiam intervenções na comunidade e um entendimento do contexto social dos pacientes. Nesse momento surge o primeiro O DSM de diagnóstico e estatística de doenças mentais (logo conhecido como DSM I), aprovado em 1952. Cria-se, então, a primeira classificação de doenças mentais a partir de critérios flexíveis que articulam as perspectivas biológica, psicanalítica e social dos transtornos mentais. Até esse momento, as pesquisas biológicas pareciam ter perdido o terreno conquistado no século XIX.

Com poucas alteraçôes será publicada, em 1968, a segunda edição desse DSM, conhecida como DSM II. Os historiadores da psiquiatria relatam a coexistência de alguns fatos que mudaram o olhar sobre as doenças mentais (AMARAL, 2004; DECKER, 2007; HORWITZ, 2007; RUSSO, 2006). Os anos 1970 foram marcados pelas críticas às instituiçôes asilares e, pouco a pouco, essas críticas se estenderam à psiquiatria. Os movimentos anticonfinamento transformam-se em movimentos antipsiquiátricos. Acumulam-se críticas levantadas por autores respeitados, como Thomas Szasz (1977), Michel Foucault (1961) ou Ervin Goffman (1961), contra o que consideravam o mito da doença mental. A essas críticas, que serão relatadas como ferozes e abusivas pelos historiadores da psiquiatria (DECKER, 2007), somam-se outras feitas pelos movimentos feministas e movimentos de homossexuais, ao mesmo tempo em que as denúncias sobre os abusos cometidos nas instituições psiquiátricas se multiplicam (AMARANTE, 1998, 2000). 
Finalmente, podem-se destacar dois fatos fundamentais para iniciar o processo de revisão da psiquiatria. O primeiro deles ocorre em 1973, após negociações com a comunidade e com o movimento de homossexuais, o DSM II retira a homossexualidade da lista de diagnósticos. Esse fato que indica um claro avanço dos direitos, ao mesmo tempo "deixava explícito que os diagnósticos psiquiátricos mantinham uma forte relação com a construção social de figuras desviantes" (AMARAL, 2004, p. 36).

O segundo fato relevante foi a publicação do artigo de Rosenham, "Being sane in insane place", na revista Science em 1973. Tratava-se de um estudo realizado por pessoas saudáveis que se declararam doentes para ingressar em um hospital psiquiátrico e que, no momento de sair da instituição, receberam o diagnóstico de "esquizofrenia em remissão" (DECKER, 2007). Esses fatos, somados às críticas de intelectuais e de movimentos pelos direitos, reclamavam uma resposta do campo da psiquiatria. Essa resposta, porém, chegou do modo mais inesperado. Longe de uma reflexão crítica dos postulados questionados pelos defensores de direitos, ocorreu uma radicalização e um retorno às velhas teses da psicologia biológica do século XIX.

Nesse momento e após longos debates, será publicado o DSM III, em 1980, inaugurando um novo modo de entender a psiquiatria. Novo em relação aos Manuais anteriormente existes, mas profundamente clássico na recuperação das velhas ideias que a psiquiatria biológica tinha defendido por mais de um século e que pareciam abandonadas, especificamente na preocupação por achar explicações biológicas, sejam hereditárias ou cerebrais aos comportamentos considerados desviados e aos sofrimentos psíquicos. No entanto, sabemos que a psiquiatria biológica continuava ativa e bem-sucedida, não somente nos tratamentos aplicados nos hospitais psiquiátricos, mas também na incipiente procura por novos medicamentos psicotrópicos que sucede a descoberta da clorpromazina em 1952.

O certo é que a recuperação das teses de Kraepelin será iniciativa desse grupo de psiquiatras da Universidade de Washington que, desde o início dos anos 1970, procurava recuperar a hegemonia perdida da psiquiatria biológica. Eles tentavam achar um modo de classificar as doenças psiquiátricas que fosse objetivo e descritivo, que pudesse ser aceito por todos e que tomasse como ponto de partida os procedimentos médicos utilizados para diagnosticar qualquer patologia biológica. Pretendiam excluir do âmbito da psiquiatria tudo aquilo que pudesse vinculá-la a discursos considerados pouco científicos, como a sociologia ou a psicanálise. 
Diversos autores já exploraram a questão de até que ponto esse grupo de psiquiatras pode ser chamado, realmente, de kraepeliniano. Existem, em relação a esta questão, alguns pontos de vista contrários. Horwitz (2007), por exemplo, argumenta que não é possível falar de continuidade entre Kraepelin e os neokraepelinianos, pois estes desconsideram uma questão que foi central para o primeiro: as pesquisas etiológicas. Existe, no entanto, coincidência na afirmação de que muitas das premissas da psiquiatria clínica de Kraepelin reaparecem nos postulados dos neokraepelinianos.

Para nos aproximar dessa controvérsia atual, tomamos como ponto de partida as teses apresentadas por Decker (2007) e por Jablensky (2007). Esses textos nos auxiliarão na tarefa de apresentar os fatos e os personagens que participaram na transformação que a psiquiatria sofreu com a publicação do DSM III. Como já destacamos, o grupo de psiquiatras da Universidade de Washington compartilhava a certeza de que somente a partir de pesquisas psiquiátricas empíricas, focadas na biologia, poderiam ser encontradas as respostas para as incógnitas sobre as doenças mentais. Seria necessário deixar de lado as perguntas etiológicas, que introduziam confusões no campo, e limitar-se a descrever os sintomas, o curso das doenças e a prestar atenção especial às historias familiares que, como no caso de Kraepelin, terão papel fundamental na determinação dos diagnósticos. Ao mesmo tempo, as pesquisas deveriam ser divulgadas entre colegas, criando uma comunicação mais fluida entre os psiquiatras. Os líderes desse grupo eram três figuras de destaque na Universidade de Saint Louis: Eli Robins (1921-94), Samuel Guze (1924-2000) e George Winokur (1925-96).

Um jovem psiquiatra que trabalhava sob orientação desses pesquisadores será o eixo articulador com o DSM III. Seu nome é John Feighner. Ele publicou em 1970 (FEIGHNER, 1979) um artigo que terá enorme repercussão na comunidade científica. O texto assinado por Feighner e por seus três mestres assentará as bases do que logo será a classificação de doenças mentais do DSM III. Era uma classificação fundamentada em dados empíricos, que não deixava lugar para avaliações subjetivas dos psiquiatras. A metodologia proposta era a revisão de um imenso número de artigos (mil, exatamente) para, a partir dos dados apresentados, deduzir critérios para estabelecer os diagnósticos de diversas desordens afetivas. Desse modo, foram construídos critérios de diagnóstico para 16 doenças psiquiátricas, dentre elas a esquizofrenia. 
O grupo considerava que para desenvolver uma classificação válida de doenças psiquiátricas, deveriam ser respeitados cinco critérios fundamentais: (1) uma descrição clínica; (2) estudos de laboratório; (3) critérios de exclusão de outras doenças; (4) estudar o curso da doença; (5) estudos referentes à família dos doentes (DECKER, 2007, p. 347).

Em 1978, um psiquiatra da Universidade Harvard chamado Gerald Klerman deu a esse grupo o nome de neokraepelinianos, pois achava que as teses por eles apresentadas implicavam uma recuperação e afirmação das antigas teses de Kraepelin, ao mesmo tempo em que evidenciavam o declínio das ideias de Freud e Meyer. Klerman (1977) sintetiza as ideias dos neokraepelinianos em nove itens que configuram algo como o credo que os unifica. Essas ideias são:

(1) A psiquiatria é um ramo da medicina.

(2) A psiquiatria deve utilizar metodologias científicas modernas e estar baseada em conhecimentos científicos.

(3) A psiquiatria trata pessoas que estão doentes e que requerem tratamento para doenças mentais.

(4) Existe uma fronteira ou limite entre normalidade e doença.

(5) As doenças mentais não são mitos. Existem muitas doenças mentais. A tarefa da psiquiatria científica, como especialidade médica, é pesquisar as causas, o diagnóstico e o tratamento das doenças mentais.

(6) O alvo da psiquiatria deve estar, particularmente, nos aspectos biológicos das doenças mentais.

(7) Deve existir uma preocupação explícita com o diagnóstico e a classificação.

(8) Os critérios diagnósticos devem ser codificados e deve existir uma área de pesquisa para validar esses critérios com diversas técnicas. Os departamentos de psiquiatria nas escolas médicas devem ensinar esses critérios, e não depreciá-los.

(9) Com a finalidade de aumentar a validade dos diagnósticos e das classificações, as técnicas estatísticas devem ser utilizadas. (DECKER, 2007, p. 348).

Esses critérios metodológicos definem o modo como a psiquiatria deveria proceder para ser considerada científica, de 1978 até hoje. Cada um desses critérios seria bem aceito por Kraepelin, e pode-se dizer que as oito versões de seu 
Manual de Psiquiatria clínica tentaram aperfeiçoar as classificações psiquiátricas a partir exatamente desses mesmos postulados, isto é, integrando os estudos realizados em outros ramos da biologia; pesquisando as causas, o diagnóstico e a terapêutica de cada doença psiquiátrica; reproduzindo os mesmos procedimentos da medicina; centrando as pesquisas e os diagnósticos no campo da biologia; utilizando estudos estatísticos e comparativos.

Destacamos aqui, fundamentalmente, as continuidades entre o discurso de Kraepelin e os neokraepelinianos, diversos autores como Horwitz (2007), por exemplo, têm apontado significativas diferenças entre esses discursos, particularmente no que se refere à procura de explicações etiológicas por parte de Kraepelin e à preocupação por descrever e enumerar sintomas característicos da psiquiatria posterior ao DSM III. Outra diferença destacada pelo autor é a preocupação de Kraepelin com o contexto de emergência da patologia na história de vida do sujeito, muitas vezes considerada pouco relevante para a psiquiatria atual.

Ainda que essas e outras diferenças possam ser apontadas, achamos relevante destacar a continuidade entre ambos os discursos. Essa identidade parece clara se observamos os trabalhos realizados pelos psiquiatras de Washington que iniciaram a recuperação desses princípios, que por cinquenta anos tinham ficado no esquecimento. Como afirma Decker (2007, p. 350), a introdução dos psicofármacos oferecia novas oportunidades de pesquisa, e os neokraepelinianos dedicaram-se a esse campo que Kraepelin imaginava promissor. Por outro lado, no fim dos anos 1970, surge um interesse crescente pelos estudos da genética.

Samuel Guze foi um dos primeiros psiquiatras americanos que realizou estudos com gêmeos para identificar o papel da herança nas doenças psiquiátricas, além de publicar diversos estudos dedicados a destacar a necessidade de remedicalizar a psiquiatria, defendendo a preeminência do modelo médico para compreender as doenças mentais. George Winokur (1996) centrou seu trabalho nos transtornos afetivos e na esquizofrenia, e escreveu um estudo sobre psicose maníacodepressiva que mostra claramente a influência de Kraepelin. Está baseado nos dados extraídos das histórias familiares de pacientes, destacando a importância da herança de caracteres patológicos.

Tendo fundamentalmente um duplo interesse em genética e em transtornos afetivos, Winokur estuda articulações de marcadores genéticos conhecidos com supostos genes de transtornos afetivos. Em seu trabalho clínico, notificou um conjunto de casos nos quais pai e filho sofrem de transtorno bipolar. Também outros tipos de transmissões pai-filho 
eram apresentados como comuns. Essa idEIA estimulou um grande número de pesqui-

sas que continuaram até o século XXI. Continuando o interesse em estudos da evolução das doenças dos neokraepelinianos, Winokur faz parte de um grupo de pesquisadores que realizam um estudo longitudinal (de seguimento por 30 a 40 anos) de pacientes diagnosticados com esquizofrenia e transtorno bipolar. (DECKER, 1970, p. 349)

Esses psiquiatras farão parte do grupo de tarefa que organiza o DSM III, no qual Feighner terá papel de destaque. A APA designa Robert Spitzer como diretor do grupo de tarefas que elaborará o DSM III. Spitzer (1979) publica trabalhos com os neokraepelinianos, desenvolve pesquisas conjuntamente e aceita, em linhas gerais, o modo de classificar as doenças proposto por Feighner, Robins, Guze e Winokur em seu estudo de 1970 (FEIGHNER, 1972). Assim, ainda que Spitzer prefira não aceitar a denominação de neokraepeliniano, fica claro que os pesquisadores da Universidade de Washington tiveram papel mais que destacado na elaboração do DSM. Todos os postulados definidos por Klerman foram integrados à sua elaboração e são considerados ainda como um marco de referência para os estudos de psiquiatria (JABLENSKY, 2007).

\section{Os avatares da degeneração}

A continuidade entre o discurso de Kraepelin e o dos neokraepelinianos parece evidenciar a permanência das velhas preocupações dos degeneracionistas. É certo que estamos longe do desvio patológico de homem normal criado à imagem de Deus de Morel, e dos estigmas e síndromes de degeneração que tanto preocupavam Magnan.

Por sua vez, Kraepelin e os neokraepelinianos compartilhavam a mesma preocupação de criar uma classificação confiável e objetiva de doenças mentais, baseada nos postulados das ciências biológicas e médicas. Queriam construir um saber tão seguro quanto a anatomoclínica. Almejavam poder determinar, a partir de um conjunto de sintomas, a causa exata, o diagnóstico e a terapêutica das doenças mentais, com tanta precisão quanto a de uma doença infecciosa. Eles tinham clareza do alcance limitado das pesquisas biológicas, neurológicas ou de anatomopatologia cerebral realizadas até esse momento, mas imaginavam um futuro no qual a ciência biológica seria capaz de desvendar os segredos do cérebro para finalmente conhecer as causas das patologias psíquicas.

Para classificar essas patologias, os teóricos da degeneração partiam de uma matriz explicativa que integrava as últimas conquistas das ciências biomédicas 
realizadas no campo da neurologia, cujo modelo eram os trabalhos de Charcot (1892), com os estudos sobre hereditariedade mórbida para os quais coletavam informações médicas a partir das histórias familiares dos pacientes. Essa mesma rede explicativa reaparece em Kraepelin, que mantém a mesma esperança nos avanços da neurologia, além do mesmo interesse em coletar histórias familiares articulandoas com estudos genéticos pré-mendelianos. Tanto os degeneracionistas quanto Kraepelin vinculam essas explicações endógenas, consideradas não conclusivas, à descrição e agrupamento de sintomas ou estigmas. Ambos realizaram estudos estatísticos e comparativos, conjuntamente com descrições do curso ou da evolução das patologias, para obter: "um conhecimento não somente do estado atual, mas da completa evolução da doença" (KRAEPELIN, 2007, p. 117).

Os postulados que guiam o trabalho dos neokraepelinianos parecem indicar uma atualização e uma continuidade desse esforço em definir, a partir das últimas descobertas da neurofisiologia cerebral, da estatística e da genética, classificações confiáveis para as patologias mentais. Seguindo os postulados de Klerman, serão incluídos estudos biológicos e excluídos outros, como os sociológicos, por exemplo. Os estudos escolhidos deverão seguir os padrões de pesquisa das ciências biológicas e médicas, de acordo com os postulados 5, 6 e 8 de Klerman.

Parece, assim, que uma mesma matriz epistemológica possibilitou o surgimento de novas síndromes de degeneração no século XIX e a emergência de um novo modo de classificar as patologias mentais nas últimas décadas do século XX. Dessa matriz epistemológica, os degeneracionistas privilegiaram os estudos sobre herança mórbida; Kraepelin, a reconstrução biológica de histórias familiares; e os neokraepelinianos Guze e Winokur, os estudos sobre marcadores genéticos de patologias mentais, evidenciando a busca de um fundamento biológico para as patologias mentais como eixo articulador desses discursos. Todos continuaram procurando nas lesōes cerebrais ou nos desequilíbrios dos neurotransmissores a etiologia das doenças. Eles compartilham, enfim, uma mesma matriz centrada em explicações endógenas, hereditárias ou cerebrais, das patologias. Uma matriz que se afirmava na exclusão de tudo aquilo que não podia ser considerado biológico. Os sofrimentos individuais, os vínculos afetivos, a precariedade do trabalho, os fracassos, as histórias de vida (plenas de situações que nada têm a ver com patologias) foram explicitamente excluídas das classificaçôes patológicas dos degeneracionistas, de Kraepelin e dos neokraepelinianos. 
Os teóricos da degeneração eram otimistas a respeito do avanço que as pesquisas biológicas poderiam trazer para identificar a causa das doenças mentais, tanto quanto hoje a psiquiatria continua otimista com o poder explicativo das neurociências, da genética, das imagens cerebrais e dos psicofármacos.

Sabemos que todas as hipóteses explicativas de sofrimentos humanos construídas até hoje sobre bases exclusivamente biológicas continuam aguardando com otimismo pesquisas futuras. No entanto, a confiança explicitada por Kraepelin em 1920 ainda permanece: "Parece-me que as perspectivas que esse tipo de reflexão oferece são bastante promissoras, apesar da pobreza de nosso conhecimento atual: elas poderiam contribuir para facilitar nossa tão difícil missão de compreensão clínica das formas de doença” (KRAEPELIN, 1920, p. 194).

\section{A modo de conclusão}

A preocupação com a herança mórbida, que aparece como matriz biológica explicativa perante a dificuldade de achar lesões ou alterações cerebrais específicas para as patologias mentais (que, no entanto, nunca deixarão de ser procuradas), foi definida por Koll como o grande mistério da medicina mental. Ele o denominou o "Oráculo de Delfos da psiquiatria" (POSTEL, 2007, p. 319), por tratar-se de um mistério que deve ser admitido sem que possamos ter nenhuma compreensão clara sobre ele. Essas explicações biológico-hereditárias fizeram parte da história da psiquiatria ao longo de todo o século XIX, para ressuscitar com força inesperada nas últimas décadas do século XX e no início do século XXI. Como sabemos, "na era da genética, a convicção do caráter hereditário de comportamentos e de problemas mentais será ainda mais pronunciada” (COFFIN, 2003, p. 256).

Permanecer aferrado a essa mitologia pode ter consequências profundas para uma classificação de patologias mentais que se pretenda universal e objetiva, pois nem os estudos de localização cerebral nem os estudos genéticos permitiram, até hoje, cumprir as promessas dos degeneracionistas ou dos neokraepelinianos, de construir um fundamento biológico sólido para legitimar as classificações realizadas pela psiquiatria.

Excluída qualquer referência ao contexto em que aparece o sintoma e excluídos os parâmetros biológicos, o que permanece é uma possibilidade infinita de agrupamentos sintomáticos, que permite uma ingerência infinita da psiquiatria nos assuntos humanos (FOUCAULT, 1999). 
AMERICAN PSYCHIATRIC ASSOCIATION. Diagnostic and Statistical Manual of Mental Disorders, 2nd ed. Washington, DC: APA, 1968.

AMERICAN PSYCHIATRIC ASSOCIATION. Diagnostic and Statistical Manual of Mental Disorders, 3rd ed. Washington, DC: APA, 1980.

AMERICAN PSYCHIATRIC ASSOCIATION. Manual de Diagnóstico e Estatistica das Perturbaçôes Mentais on line. 4. Ed. Washington DC: APA, 1994.

CHARCOT, J.; MAGNAN V. De l'onomatomanie. Archives de neurologie, v. 23, n. 69, 1892.

COFFIN, J. La Transmission de la Folie- 1850-1914. Paris: Harmattan, 2003.

DECKER, A. How Kraepelinian was Kraepelin? How Kraepelinian are the neoKraepelinians? from Emil Kraepelin to DSM-III. History of Psychiatry, Los Angeles, v. 18, n. 3, p. 381-388, 2007.

FEIGHNER, J.P. et al. Diagnostic criteria for use in psychiatric research. Archives of General Psychiatry, v. 26, p. 57-63, 1972.

FEIGHNER, J.P. Nosology: a voice for systematic data-oriented approach [Editorial]. American Journal of Psychiatry, n. 136, p. 1173-4, 1979.

FOUCAULT, M. Les anormaux. Paris: Seuil, 1999.

HORWITZ, A.; WAKEFIELD, J. The Loss of Sadness. Oxford: Oxford University Press, 2007. HACKING, I. L'âme réécrite : étude sur la personnalité multiple et les sciences de la mémoire. Les empecher de penser en rond. Paris. PUF, 2006.

JABLENSKY, A. Living in a Kraepelinian world: Kraepelin's impact on modern psychiatry. History of Psychiatry, Los Angeles, v. 18, n. 3, p. 381-388, 2007.

KLERMAN, G.L. Mental illness, the medical model, and psychiatry. Journal of Medicine and Philosophy, v. 2, n. 3, p. 220-43, 1977.

KRAEPELIN, E. As formas de manifestação da insanidade Rev. Latinoam. Psicopat. Fund., São Paulo, v. 12, n. 1, p. 167-194, mar. 2009.

- Clinical Psychiatry. A Text book for students and physicians. New York: Macmillan, 1904.

- Clinical Psychiatry. A Text book for students and physicians. New York: Macmillan, 1907.

. Leçons cliniques sur la démence précoce et la psychose maniaco-depressive. Paris. Harmattan, 1997. . Lectures on clinical psychiatry. Michigan: W. Wood, 1913.

On the Question of Degeneration - 1908. History of Psychiatry. London, v. 18, p. 398-404, 2007. 
MAGNAN, V. Recherches sur les centres nerveux. Alcoolisme, folie des héréditaires dégénérés. Paris: Masson, 1893.

MOREL, B.A. Rapport fait à la Société medico-psicologique sur le Traité de Dégénérescence. Annales médico-psicologiques, Paris, n. 3, p. 456-460, 1859.

. Traité des dégénérescences physiques, intellectuelles et morales de l'espèce humaine et des causes qui produisent ces varieties maladives. Paris: Bailliére, 1857.

RUSSO, J.; VENANCIO, M.T. Classificando as pessoas e suas perturbações: a "revolução terminológica” do DSM III. Rev. Latino-americana de Psicopatologia Fundamental, ano IX, n. 3, set 2006 .

POSTEL, J. Éléments pour une Histoire de la Psichiatrie occidentale. Paris : Harmattan, 2007. Introduction à 'Leçons cliniques sur la démence précoce et la psychose maniacodepressive’. Paris: Harmattan, 1997.

. Historia de la psiquiatria. Mexico : Fondo de Cultura Económica, 1987.

SPITZER, R.L.; FORMAN, J.B.W. DSM-III Field Trials II. Initial experience with the multiaxial system. American Journal of Psychiatry, v. 136, n. 6, p. 818-20, 1979.

SPITZER, R. Introductio. In: HORWITZ, A.; WAKEFIELD, J. The Loss of Sadness. Oxford: Oxford University Press, 2007.

\section{Notas}

${ }^{1}$ A teoria da degeneração se inicia com Morel em 1857, e atinge com V. Magnan (1893) caráter institucional e aceitabilidade na comunidade científica francesa e internacional. Influenciou fortemente os debates sobre psiquiatria, criminologia e higiene pública na segunda metade do século XIX e nas primeiras décadas do século XX (FOUCAULT, 1999; COFFIN, 2003; HACKING, 2006).

${ }^{2}$ Entende-se por "estigmata" ou estigma as marcas observadas no corpo, fundamentalmente no rosto e cabeça, que assinalam algum desvio da normalidade (entendida como aquilo que aparece com maior frequência na população). A identificação desses estigmas não parece ter sofrido grandes modificaçōes na psiquiatria da segunda metade do século XIX e primeiras décadas do século XX, mantendo-se referências semelhantes ao tamanho da cabeça, posição das orelhas, dos olhos, etc. (FOUCAULT, 1999; COFFIN, 2003).

3 “O DSM foi declarado um Manual ateórico baseado em princípios de testabilidade e verificação a partir dos quais cada transtorno é identificado por critérios acessíveis à observação e à mensuração empírica. Fundamenta-se em uma crítica ao modo anterior de classificação, baseado em uma pretensa etiologia dos transtornos mentais, ou seja, em processos subjacentes, inferidos pelo clínico e não passíveis de uma observação empírica rigorosa. O pressuposto empirista implicado em uma posição ateórica, e por isso objetiva, tem afinidades evidentes com uma visão fisicalista da perturbação mental" (RUSSO, 2006, p. 465). 


\section{The morbid heredity: from Kraepelin to the Neo-Kraepelinians}

We analyze here the problems of the morbid heredity in the different editions of the work of Emil Kraepelin Clinical Psychiatry: a Text-book for students and physicians. We study the persistence and continuity of the main thesis of Kraepelin, included the hereditary etiology of mental pathologies, in the contemporary Psychiatry that is self-defined as Neo-kraepelinian. With this goal we study, firstly, the theoretical and conceptual articulations that exist between the idea of morbid constitution and the strategies proposed by Kraepelin for the realization of the psychiatric interviews. Next, we consider the place reserved to the studies of the morbid heredity in the historical context in which the NeoKraepelinian Psychiatry emerged, specifically since the elaboration of the DSM III.

> Key words: Heredity; mental diseases; Kraepelin; DSM; degeneration. 